\title{
The Need for Geriatric Dental Education
}

\author{
Shilpa Shetty
}

Published online: 28 January 2014

(C) Indian Prosthodontic Society 2014

Dear colleagues.

Wish you all a happy, prosperous and a productive year!!

An eventful year has passed by.

And yet there is so much more to be achieved!!

And so much more to give back to the society.

There is a rapid growth of the geriatric population amidst us.

The report, by the United Nations Population Fund, found the number of over-60s in our country will increase from around 100 million today to more than 300 million by 2050 and warned the government to prepare for the additional strain this will put on families and health and welfare services. It also predicted the number of over-80s will increase seven fold. "These findings underline that with a growing elderly population in the country there is a need to strengthen geriatric care services in the existing public health system so that the increasing care demands of the elderly can be met," the report warned. It also said the government must increase the availability and take-up welfare benefits for the elderly poor [1].

The rapid growth in the elderly population in a developing country such as India poses social and financial challenges by causing a shift towards non-communicable diseases and increase in chronic diseases such as cardiovascular disease, hypertension, diabetes and cancer. The link between oral health and general health are particularly pronounced in older populations and impairs their quality of life [2].

To address the increasing health challenges and demands of a growing geriatric population, undergraduates and

S. Shetty $(\square)$

Department of Prosthodontics, Department of Implantology,

V.S. Dental College \& Hospital, Bangalore 560004, India

e-mail: editor.ipsjournal@gmail.com graduate students in dental schools should be given comprehensive or holistic health assessment training. Costeffective modern educational strategies and educational tools such as problem-based learning will help to overcome the dearth of trained faculty in geriatric dentistry [3].

Multidisciplinary health-care approaches and extended health-care team work are of vital importance to older patients who could benefit physically and psychologically from more efficient dental treatment. Measures to help older people remain healthy and active are a necessity in developing countries such as India for effective social and economic development [4].

The need for geriatric dental education was realized in the late 1970s. Yellowitz and Saunders [5], Kress and Vidmar [6] and Ettinger [7] were the pioneers who championed the cause for special education needs for geriatric dentistry.

Geriatric dentistry is better developed in most of the developed nations such as the USA, Canada, UK, Australia, and the European nations, as compared to the developing world.

As stated by Nitschke [8], gerodontology does not compete with other traditional specialties but only complements them. They have identified eleven domains in which geriatric dentistry was included in various basic sciences and clinical subjects of dentistry after analysis of the undergraduate curriculum in Germany, Austria, and Switzerland. This can provide the starting point to develop a curriculum for various categories of courses in geriatric dentistry.

In developing countries, geriatric dentistry has not received the attention of dental professionals and policymakers, though one-sixth of the total world population of elderly now lives in the developing countries of Southeast Asia [4].

It is time that the academicians and policy makers promote geriatric dentistry education at the undergraduate and 
postgraduate levels in our country whereby the teaching of geriatric dentistry starts right from the first year BDS.

Therefore the society at large would benefit if we stress the need to educate our students so that they will be equipped with competitive skills which will enable them to treat the growing geriatric population. In this way we can contribute to enhancing the quality of life of the elderly population.

\section{References}

1. World population prospects: the 2000 revision (2001) Department of Economic and Social Affairs. United Nations Population Division, New York
2. Thomas S (2013) The need for geriatric dental education in India: the geriatric health challenges of the millennium. Int Dent $\mathbf{J}$ 63(3):130-136

3. Shah N (2010) Teaching, learning and assessment in geriatric dentistry: researching models of practice. J Dent Educ 74:20-28

4. World Health Organization Working Panel on Professional Training (1972) The sociology of professional training and health manpower: summary report. World Health Organization, Geneva

5. Yellowitz J, Saunders MJ (1989) The need for geriatric dental education. Dent Clin North Am 1:11-15

6. Kress GD, Vidmar GC (1985) Critical skills assessment for the treatment of geriatric patients. Spec Care Dent 5(3):127-129

7. Ettinger RL (1983) Geriatric dental curricula and the needs of the elderly. Paper presented at the symposium on clinical geriatric dentistry: biomedical and psychosocial aspects, Chicago, June

8. Nitschke I, Muller F, Ilgner A, Reber T (2004) Undergraduate teaching in gerodontology in Austria Switzerland and Germany. Gerodontology 21:123-129 